6 Goldberg RJ, Gurwitz J, Yarzebski J, Landon J, Gore JM, Alpert JS, et al Patient delay and receipt of thrombolytic therapy among patients with acute myocardial infarction from a community-wide perspective. Am J Cardiol 1992;70:421-5.

7 Goff DC, Sellers DE, McGovern PG, Meischke H, Goldberg RJ, Bittner V, et al. Knowledge of heart attack symptoms in a population survey in the United States: the REACT trial. Rapid early action for coronary treatment. Arch Intern Med 1998;158(21):2329-38.

8 Goff DC, Feldman HA, McGovern PG, Goldberg RJ, Simons Morton DG, Cornell CE, et al. Prehospital delay in patients hospitalized with heart attack symptoms in the United States: the REACT trial. Am Heart J 1999;138:1046-57.

9 Ruston A, Clayton J, Calnan M. Patients' action during their cardiac event: qualitative study exploring differences and modifiable factors. BMJ 1998;316:1060-4.

10 Horne R, James D, Petrie K, Weinman J, Vincent R. Patients interpretation of symptoms as a cause of delay in reaching hospital during acute myocardial infarction. Heart 2000;83:388-93.

11 McKinley S, Moser DK, Dracup K. Treatment-seeking behavior for acute myocardial infarction symptoms in North America and Australia. Heart Lung 2000;29:237-47.

12 Blohm MB, Hartford M, Karlson BW, Luepker RV, Herlitz J. An evaluation of the results of media and educational campaigns designed to shorten the time taken by patients with acute myocardial infarction to decide to go to hospital. Heart 1996;76:430-4.

13 Ho MT, Eisenberg MS, Litwin PE, Schaeffer SM, Damon SK. Delay between onset of chest pain and seeking medical care: the effect of public education. Ann Emerg Med 1989;18:727-31.
14 Meischke H, Dulberg EM, Schaeffer SS, Henwood DK, Larsen MP, Eisenberg MS. "Call fast, call 911": a direct mail campaign to reduce patien delay in acute myocardial infarction. Am J Public Health 1997;87:1705-9.

15 Luepker RV, Raczynski JM, Osganian S, Goldberg RJ, Finnegan JR, Hedges JR, et al. Effect of a community intervention on patient delay and emergency medical service use in acute coronary heart disease: the ap emergency

16 Gaspoz JM, Unger PF, Urban P, Chevrolet JC, Rutishauser W, Lovis C, et al. Impact of a public campaign on pre-hospital delay in patients reporting chest pain. Heart 1996;76:150-5

17 Herlitz J, Blohm M, Hartford M, Karlson BW, Luepker RV, Holmberg S, et al. Follow-up of a 1-year media campaign on delay times and ambulance use in suspected acute myocardial infarction. Eur Heart J 1992;13:171-7

18 Rustige J, Schiele R, Burczyk U, Koch A, Gottwik M, Neuhaus KL, et al. The 60 minutes myocardial infarction project. Treatment and clinical outcome of patients with acute myocardial infarction in Germany. Eur Heart J 1997;18:1438-46.

19 Dracup K, Moser DK. Beyond sociodemographics: factors influencing the decision to seek treatment for symptoms of acute myocardial infarction. Heart Lung 1997;26:253-62.

20 Department of Health. National service framework for coronary heart disease. London: Stationery Office, 2000.

21 Roupie E. L'infarctus du myocarde au service d'accueil et d'urgences: une entite particulière ou la prédominance des atypies?... [Myocardial infarct in the admissions and emergency service: a particular entity or predominant atypia?...]. Presse Med 1998;27:1636-7.

(Accepted 29 November 2001)

\title{
Prospective audit of records of deceased patients received in hospital mortuary
}

\author{
Y L Hock, P Stewart, E Livesley
}

Mortuary services in hospitals have generally been given little attention by clinicians, the media, or the public. However, recent stories about improper storage of bodies and organs have generated public interest in both pathology and mortuary services. ${ }^{1-3}$

Response to the media stories shows that the public expects the standards of care and attention given to the deceased to be the same as those for living patients. However, our experience, and that of pathology colleagues, suggests that clinical staff do not pay enough attention to the documentation related to deceased patients. Although this is understandable given the increasing workload of clinical staff and staff shortages, it is unacceptable. To investigate the errors or omissions in the documentation accompanying deceased patients, we audited the documents accompanying all deceased patients in the hospital over four years.

\section{Methods and results}

We prospectively audited the documentation relating to 7761 bodies received in the mortuary of the Walsall Hospitals NHS Trust during 1996-2000. Bodies were received from funeral directors and ambulance crews as well as hospital wards. We checked wrist bands, labels, and identification papers against the patients registration details on the hospital patient management system for any discrepancies. We also checked accuracy of recording the presence of a pacemaker and property for each body. Bodies for which there was one or more discrepancy were classified as failed cases. Annual failure rates are expressed as the percentage of failures in a financial year (April to March). The study was part of an ongoing internal quality assurance audit, and ward managers and funeral directors were
Walsall Hospitals NHS Trust, Walsall WS2 9PS

Y L Hock consultant histopathologist P Stewart medical technical officer (mortuary)

Department of Public Health Medicine, Walsall Health Authority, Lichfield House, Walsall WS1 1TE

E Livesley epidemiologist

Correspondence to: Y L Hock

Hocky@wht.walsallh-tr. wmids.nhs.uk

BMJ 2002;324:1009-10

Accuracy of documentation for bodies received in hospital mortuary

\begin{tabular}{|c|c|c|c|c|c|c|c|c|}
\hline \multirow{2}{*}{$\begin{array}{l}\text { Financial year } \\
\text { (April-March) }\end{array}$} & \multirow{2}{*}{$\begin{array}{l}\text { Total No of } \\
\text { bodies }\end{array}$} & \multirow{2}{*}{$\begin{array}{l}\text { No (\%) with } \\
\text { documentation } \\
\text { failure }\end{array}$} & \multicolumn{6}{|c|}{ Type of discrepancy (hospital deaths only) } \\
\hline & & & Name* $^{*}$ & Address & Unit No & Wristband & Property & Pacemaker \\
\hline \multicolumn{9}{|l|}{ 1996-7: } \\
\hline All bodies & 1920 & $196(10.2)$ & & & & & & \\
\hline Hospital deaths & 1484 & $177(11.9)$ & 12 & 8 & 24 & 87 & 38 & 8 \\
\hline \multicolumn{9}{|l|}{ 1997-8: } \\
\hline All bodies & 1835 & $143(7.8)$ & & & & & & \\
\hline Hospital deaths & 1312 & $139(10.6)$ & 6 & 2 & 14 & 73 & 27 & 17 \\
\hline \multicolumn{9}{|l|}{ 1998-9: } \\
\hline All bodies & 1947 & $95(4.9)$ & & & & & & \\
\hline Hospital deaths & 1363 & $94(6.9)$ & 3 & 11 & 9 & 49 & 16 & 6 \\
\hline \multicolumn{9}{|l|}{ 1999-2000: } \\
\hline All bodies & 2059 & $60(2.9)$ & & & & & & \\
\hline Hospital deaths & 1460 & $58(4.0)$ & 4 & 6 & 7 & 28 & 11 & 2 \\
\hline
\end{tabular}

*Minor typographical errors are excluded. 
sent memorandums pointing out any errors and omissions every six months.

In 1996-7, the failure rate for bodies from all sources was $10.2 \%$ (table). This figure fell in the study period to $2.9 \%$ in $1999-2000$. The bodies received from the hospital accounted for most cases of failed documentation. When the failure rate was calculated for hospital deaths alone, it fell from $11.9 \%$ in 1996-7 to $4.0 \%$ in $1999-2000$.

\section{Comment}

That the documentation of about $10 \%$ of deceased patients contained errors at the beginning of the study suggests that clinical staff were paying insufficient attention to the identification and details of deceased patients. Although some of the discrepancies were arguably less important, such as errors in unit number or address, a substantial proportion could have had serious consequences. These include misidentification of the body (body received in the mortuary with the wrong name) or property and non-notification of pacemakers.

Pathology is one of the most intensely scrutinised medical specialties. Clinical Pathology Accreditation (UK) sets standards for medical laboratories and mortuaries and insists on external quality control measures and regular internal audits. However, the mandatory quality assurance procedures refer only to the internal quality control of all examinations and do not specifically refer to mortuary services. ${ }^{4}$ Our experience of inspections by Clinical Pathology Accreditation is that little emphasis is put on regular internal quality control audit of the mortuary or on any other internal quality assurance procedures. The error rate fell during our study, probably because staff were regularly alerted to errors as part of the audit. We therefore believe that such audits are essential for a mortuary to run effectively and safely and to gain public confidence.

We thank Colin Humphries and Rachel Jones for collecting routine data and Tony Board for suggesting a regular mortuary audit. We also thank Angela Turner for typing the manuscript.

Contributors: PS was responsible for initiating and coordinating the audit and data analysis. YLH was responsible for reviewing the literature, interpreting the results, and writing and editing the paper. EL was responsible for statistical analysis and also helped edit the paper. YLH is the guarantor.

Funding: None.

Competing interests: None declared.

1 Lawrence J. Milburn blames hospitals manager for allowing corpses to be left on chapel floor. Independent $2001 \mathrm{Jan} 17$. www.independent.co.uk/ story.jsp?story $=51331$ (accessed 8 Jan 2002).

2 Carvel J, Branigan T. Hospital admits storing 12 bodies in boilerhouse. Guardian 2001 Jan 19. www.guardian.co.uk/Archive/Article/ $0,4273,4119764,00$.html (accessed 8 Jan 2002).

3 Hunter M. Alder Hey report condemns doctors, management, and coroner. BMJ 2001;322:255.

4 Clinical Pathology Accreditation (UK) Ltd. Standards for the medical laboratory. www.cpa-uk.co.uk (accessed 27 Mar 2001).

(Accepted 22 October 2001)

\section{RESEARCH POINTERS}

\section{Unexplained differences in sex ratios at birth in Europe and North America}

The

male:female ratio at birth by latitude in Europe is the reverse of that in North America. A temperature related effect cannot account for this

Paediatric Department, St Luke's Hospital, Guardamangia MSD 09, Malta Victor Grech consultant continued over

BMJ 2002;324:1010-1
In mammals, male live births exceed female ones. In humans, the ratio of male births to total births is expected to be 0.515. In Europe during 1990-5 this differed significantly with increasing geographical latitude. ${ }^{1}$ We analysed and compared the male to female ratio in Europe and North America over 50 years.

\section{Methods and results}

We obtained annual data on male and female live births from the World Health Organization (WHO) for the North American continent for 1958-97 and for European countries for 1950-99. Overall <3\% of data were missing.

European countries were banded by latitude. Southern countries (latitude $35-40^{\circ}$ ) included Bulgaria, Greece, Italy, Malta, Portugal, and Spain. Central Europe (40-55 $5^{\circ}$ included Austria, Belgium, Czech Republic, France, Germany, Hungary, Ireland, Luxembourg, Netherlands, Poland, Romania, Switzerland, and the United Kingdom. Nordic countries $\left(>55^{\circ}\right)$ include Denmark, Finland, Iceland, Norway, and Sweden. North America was divided by latitude into Canada $\left(>50^{\circ}\right)$, the United States $\left(30-50^{\circ}\right)$, and Mexico $\left(<30^{\circ}\right)$.
We analysed contingency tables using $\chi^{2}$ and $\chi^{2}$ for trend and obtained 95\% confidence intervals for ratios by using the Fleiss equations. $\mathrm{P} \leqslant 0.05$ was taken as significant.

\section{Results}

Significantly more boys were born in southern countries (table) than in central Europe $\left(\chi^{2}=57\right.$, $\mathrm{P}<0.0001)$ or the Nordic countries $\left(\chi^{2}=8.8, \mathrm{P}=0.003\right.$; $\chi^{2}$ for trend $\left.=120, \mathrm{P}<0.0001\right)$. The difference between central Europe and the Nordic countries was not significant. All had a male to female ratio $<0.515$, with a resultant male birth deficit of 12744 in the Mediterranean, 212780 in central Europe, and 13169 in the Nordic countries (total deficit of male births 238 693).

A low male to female ratio was found in Mexico, a higher ratio in the United States, and an even higher ratio in Canada ( $\chi^{2}$ for trend $=57, \mathrm{P}<0.0001$ ). All had a male to female ratio $<0.515$, with a resultant male birth deficit of 21993 in Canada, 410932 in the United States, and 521789 in Mexico (total deficit 954 714) 